\title{
Sjogren-Larsson Syndrome: A Rare Differential Diagnosis of Cerebral Palsy
}

\author{
Kursat Bora Carman ${ }^{\mathrm{a}, \mathrm{b}}$, Sevgi Yimenicioglu ${ }^{\mathrm{a}}$, Arzu Ekici ${ }^{\mathrm{a}}$, Ayten Yaku
}

\begin{abstract}
Sjogren-Larsson syndrome (SLS) is an autosomal recessively inherited neurocutaneous disorder caused by a deficiency of the microsomal enzyme fatty aldehyde dehydrogenase. Major findings of Sjogren-Larsson Syndrome are ichthyosis, mental retardation and spasticity in the form of diplegia or quadriplegia. Neurologic symptoms and signs appear during the first or second year of life and consist of delay in reaching motor milestones due to spasticity. Due to these physical findings patients with SLS might be misdiagnosed as cerebral palsy. We report a case presented with icthyosis and learning difficulty and previously diagnosed as cerebral palsy.
\end{abstract}

Keywords: Sjogren-Larsson Syndrome; Ichthyosis; Mental retardation; Cerebral palsy

\section{Introduction}

Sjogren-Larsson syndrome (SLS) is an autosomal recessive neurocutaneous disorder caused by a deficiency of the enzyme fatty aldehyde dehydrogenase which has an important role in lipid and leukotrien $\mathrm{B}_{4}$ mechanism which leads abnormal lipid accumulation occurs in the skin and central nervous system [1]. It has an incidence of 0.4/100.000 worldwide [2]. Major findings of Sjogren-Larsson Syndrome are congenital ichthyosis, mental retardation and spasticity in the form of diplegia or quadriplegia [3]. Neurologic symptoms and signs appear during the first or second year of life and consist of delay in reaching motor milestones due to spasticity. Nearly half of the patients are non-ambulatory and most others re-

Manuscript accepted for publication October 4, 2012

\footnotetext{
${ }^{a}$ Department of Pediatric Neurology, Eskisehir Osmangazi University, Faculty of Medicine, Eskisehir, Turkey

${ }^{\mathrm{b}}$ Corresponding author: Kursat Bora Carman, Batikent Mah. Vehbi Dincerler Cad. Sena Apt. Kat; 5 D; 9 Ibrahimli-Sehitkamil, 27000 Gaziantep, Turkey. Email: kbcarman@gmail.com
}

doi: http://dx.doi.org/10.4021/ijcp58w quire braces or churches to walk [4]. Due to these physical findings patients with SLS might be wrongly diagnosed as cerebral palsy.

Here we reported a case presented with difficulty in learning and diagnosed as Sjogren-Larsson syndrome.

\section{Case Report}

Thirteen-year-old male patient was admitted to hospital with learning difficulties. In his history, he has been itching and his skin has been peeled off since birth with severe pruritus. Although he has been continued to fifth-grade elementary school, he was illiterate. He was born in 32th-week of gestation with 2,400 grams birth weight. He had gained neck control in 7th month, he had stood still in first year and he had walked by 22 months of age. He was previously diagnosed and treated as cerebral palsy. In physical examination his body weight was $23 \mathrm{~kg}(<5$ percentile), length was 130 $\mathrm{cm}(<5$ percentile $)$ and head circumference was $51 \mathrm{~cm}$. He can make sentences but his speech was not fully comprehensible. Cranial nerve examination was normal. Muscle tone was increased in lower extremities and deep tendon reflexes were hyperactive. Babinski reflex was bilaterally positive. He was walking at his finger tips. Dryness and peeling of the skin were prominent on in trunk and legs (Fig.1).

In laboratory, complete blood count, peripheral blood smear, complete urine analysis, thyroid function tests, blood and urine aminoacid analysis, creatine kinase levels were normal. Electroencephalography and echocardiography were normal. Wechsler Intelligence Scale for Children-revised test showed mild mental retardation. Brain Magnetic resonance imaging showed hypomyelinization and mild cortical atrophy (Fig. 2).

\section{Discussion}

Sjogren Larsson syndrome is characterized by congenital ichthyosis, mental retardation and spasticity. Manifestations of SLS are attributed to a defect in the metabolism of long chain fatty acids. This results in the accumulation of fatty al- 


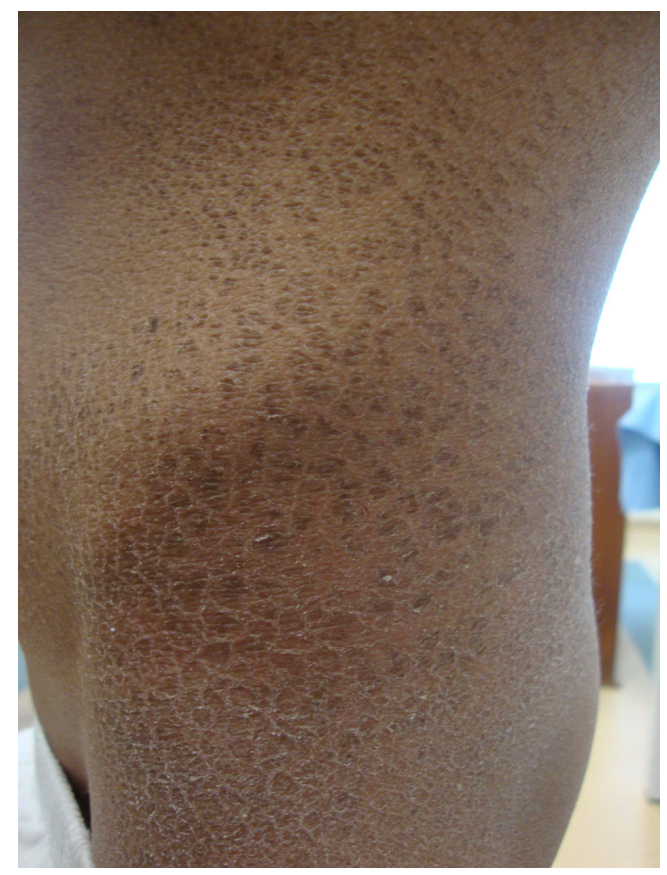

Figure 1. Common ichthyosis in whole body.

cohols in the skin and myelin of the central nervous system. The ichthyosis in SLS has characteristic appearance with its prominent generalized hyperkeratosis and remarkable brownish yellow color and is prominent in the flexure areas, nape of the neck, trunk and extremities. All patients also suffer from severe pruritus like our patient. The presence of pruritus in SLS contrast with other icthyotic skin disorders, which are generally non-icthing [4]. Although it is usually the presenting symptom of patients, ichthyosis might be in the 23th week of gestation prenatally $[5,6]$.

Neurological features are variable; however, mental retardation and developmental delay are usually obvious at 1 to 2 years of age. Spasticity may be apparent before the age of 3 years and is more severe in the lower limbs. The majority of patients becoming wheelchair dependent for mobility over time and contractures developed $[1,5,6]$. Neuroimaging reports described brain atrophy and white matter disease characterized by hypomyelination as our case. These findings are due to accumulation of lipid metabolism products in central nervous system $[4,7]$.

Most patients with SLS have speech disorders and learning disability. The academic performance of our case was poor and speech was not fully comprehensible. It was shown that early speech language therapy might improve speech [8].

Nearly all patients with SLS have the history of prematurity, although complications of prematurity are not usually seen in these patients. All of the SLS patients were born before 38th week of gestational age reported by Willemsen et al [4] and mean gestational age was 35.3 weeks. Leukotriene

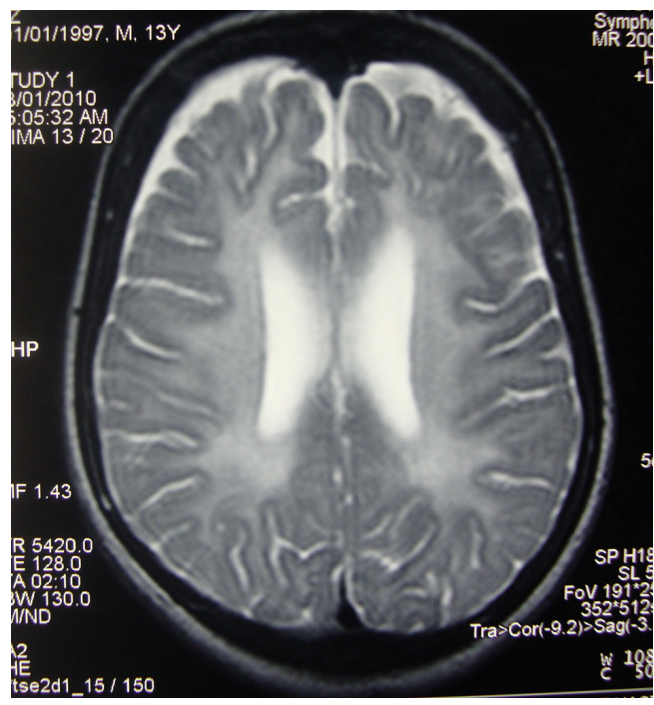

Figure 2. Hypomyelinization and cortical atrophy.

B4 metabolism disorders are thought to be the reason of prematurity. Spasticity and history of prematurity might lead to diagnose these patients as cerebral palsy. It was learned as our case had been followed as cerebral palsy.

Most characteristic eye finding of SLS is macular dystrophy with intraretinal crystals and foveal pseudocysts [1, 4]. Detailed opthalmologic examination can not be done because he was uncooperated.

Sjogren Larsson syndrome can be diagnosed with physical examination findings. Genetic analysis can support the diagnosis. There is not a genotype phenotype relationship $[1,3,4]$. We can not make genetic and enzymatic laboratory study.

In conclusion, in a patient with prematurity, mental retardation, spasticity and ichtyosis, SLS has to be in the differential diagnosis. We want to emphasize that dermatological examination should be done in patients presenting with spastictity and mental retardation.

\section{Conflict of Interest}

None.

\section{Role of Funding Source}

None.

\section{References}

1. Caglayan AO, Gumus H. A very rare neurocutaneous disorder in 2 siblings: Sjogren-Larsson syndrome. J 
Child Neurol. 2010;25(8):1003-1005.

2. Gordon N. Sjogren Larsson syndrome. Developmental Medicine \& Child Neurology. 2007;49(2):152-4.

3. Rizzo WB. Sjogren-Larsson syndrome: molecular genetics and biochemical pathogenesis of fatty aldehyde dehydrogenase deficiency. Mol Genet Metab. 2007;90(1):1-9.

4. Willemsen MA, L IJ, Steijlen PM, Rotteveel JJ, de Jong JG, van Domburg PH, Mayatepek E, et al. Clinical, biochemical and molecular genetic characteristics of 19 patients with the Sjogren-Larsson syndrome. Brain. 2001;124(Pt 7):1426-1437.

5. Kousseff BG, Matsuoka LY, Stenn KS, Hobbins JC, Ma- honey MJ, Hashimoto K. Prenatal diagnosis of SjogrenLarsson syndrome. J Pediatr. 1982;101(6):998-1001.

6. Jagell S, Liden S. Ichthyosis in the Sjogren-Larsson syndrome. Clin Genet. 1982;21(4):243-252.

7. Willemsen MA, Van Der Graaf M, Van Der Knaap MS, Heerschap A, Van Domburg PH, Gabreels FJ, Rotteveel JJ. MR imaging and proton MR spectroscopic studies in Sjogren-Larsson syndrome: characterization of the leukoencephalopathy. AJNR Am J Neuroradiol. 2004;25(4):649-657.

8. Fuijkschot J, Maassen B, Gorter JW, Gerven M, Willemsen M. Speech-language performance in Sjogren-Larsson syndrome. Dev Neurorehabil. 2009;12(2):106-112. 